\title{
A novel framework of ERP implementation in Indian SMEs: Kernel principal component analysis and intuitionistic Fuzzy TOPSIS driven approach
}

\author{
Indranil Ghosh* and Sanjib Biswas
}

Department of Operations Management, Calcutta Business School, Bishnupur - 743503, South 24 Parganas, West Bengal, India

\begin{tabular}{l}
\hline C H R O N I C L E \\
\hline Article history: \\
Received December 5, 2015 \\
Received in revised format \\
February 162016 \\
Accepted July 12016 \\
Available online \\
July 252016 \\
\hline Keywords: \\
Enterprise Resource Planning \\
Small and Medium Enterprises \\
(SMEs) \\
Critical Success Factors (CSFs) \\
Kernel Principal Component \\
Analysis (KPCA) \\
Intuitionistic Fuzzy set theory \\
TOPSIS
\end{tabular}

\section{Introduction}

Revolutions in Information Technology (IT) have enabled organizations to leverage sharing of information for achieving effective coordination and control across their supply chains and thereby gaining competitive advantage. Over the last few decades, Enterprise Resource Planning (ERP) system has emerged as one of key enablers for achieving integration among the partners across the supply chain (Orouji, 2015). ERP is basically a modular and packaged business software solution for streamlining, integration and automation of majority of internal and external business processes of any organization (Huin, 2004). It is a real time and three layered (application layer, database layer and web layer) enterprise wide solution. Application layer enables to host and automate different functional business activities associated with manufacturing, materials management, financial management,

* Corresponding author.

E-mail address: fri.indra@gmail.com (I. Ghosh)

(C) 2017 Growing Science Ltd. All rights reserved. doi: $10.5267 /$ j.ac.2016.7.004 
human resources practices, sales and distribution, etc. using the data base layer as a common platform and web layer for seamless integration. Successful implementation of commercial ERP packages result in improved productivity, better utilization of resources, enhanced quality and therefore assist organizations in gaining competitive edge (Rao, 2000; Yusuf et al., 2006; Habibzadeh et al., 2016). Architecture and impact of ERP system have been well discussed in literature (Shanks, 2000; Siau, 2004). As a result of which organizations ranging from large scale to small and medium scale attempt to leverage the usefulness of ERP system by making big investments.

Over the years small and medium enterprises (SMEs) have been playing significant role in economic development. Findings from researches conducted by researchers and practitioners have revealed that, SMEs (Abid et al., 2012) are one of the growth drivers contributing around 80 percent of economic growth globally (Jutla et al., 2002). This is even more prevalent in the context of Indian economy where SMEs are contributing around 45 percent to national GDP (Annual report: Ministry of Micro, Small and Medium enterprises, 2014-15). This sector has enormous role in development of backward areas, employment generation and wealth creation. However, the global economic meltdown has put a restriction to organizations in terms of resource scarcity. The key issue is to consolidate resources cutting down waste from the system. Thus, it is imperative for organizations to integrate all their functions and collaborate with their partners in order to achieve sustainable growth. This essentially necessitates implementation of ERP even for the SMEs. Thus business process management through ERP can act as a major driver for SMEs to sustain and excel in competitive market. However, it must be noted that, many researchers have reported failure cases of ERP adoption. Academicians and practitioners have been carrying out rigorous studies to assess the critical success factors, obstacles, benefits of Implementation of ERP software. Different models to manage the entire ERP project management have been evolved as well. Most of these work have mainly targeted the large scale organizations belonging to different industrial sectors in both developed and developing countries. Unlike Large organizations, SMEs on the other contrary sometimes face dilemma over investing in ERP portfolio due to their nature of business. This is largely due to their scarce and limited human, intellectual and capital resources. An increased rate of interest in the said sector for ERP implementation has been observed too. Due to inadequate experience, lack of skill-sets and limited resources, SMEs often struggle to reach to fulfill their potential. In this work initially survey of existing literature has been made to understand the key issues of ERP implementation process. From the works made by several researchers and academicians, it is seen that, the factors like top management commitment and leadership, communication, involvement, business process reengineering, training, change management etc. are having significantly impact on process integration and streamlining, operational performance improvement and strategic decision making. In other words, these are the factors are critically significant for achieving success and determines success or failure of ERP implementation (Knight, 2000; Motwani et al., 2002).

Woo (2007) thoroughly investigated the ERP implementation project in a Chinese organization and found top management, project team, project management, process change, education and training and communication as key drivers of the process. Importance of proper training in successful implementation has been discussed in literature (Sumner, 1999). Holland et al. (1999) emphasized on strategic factors for successful implementation. On other hand, dedicated research studies have been made to quantify the benefits of ERP system as well (Mandal \& Gunasekaran, 2002; Palaniswamy \& Frank, 2000; Vogt, 2002). Research framework of this study is composed of two parts. At first, Questionnaire has been framed and survey has been conducted to recognize the key CSFs for ERP project management in SME sector of India. In general majority of the empirical research deploy factor analysis using traditional principal component analysis (PCA) as a factor extraction method for to detect key constructs. Kernel Principal Component Analysis (KPCA) as a nonconventional method has been adopted here to carry out the task. Results have been validated as well. Then to evaluate the relative effectiveness of the extracted factors, Intuitionistic Fuzzy Set theory based Technique of Order Preference by Similarity to Ideal Solution (TOPSIS) (Hwang \& Yoon, 1981) method has been applied to explore the relationships between some of the well-known ERP benefits and the respective factors. 
A secondary questionnaire is framed to serve the purpose by collecting expert opinion. Basua, R., Upadhyay and Dan (2011) identified and prioritized the factors influencing proper implementation of ERP systems in a business organization particularly for Indian small and medium businesses (SMBs).

The rest of this paper is structured as follows. Section 2 discusses about the methodology of KPCA where in section 3, the framework of Intuitionistic Fuzzy TOPSIS is narrated. Results are mentioned and discussed in section 4. In section 5, key findings and significance of the work are highlighted. Finally, section 6 put forth concluding remarks along with future scope of work.

\section{Factor Analysis Using Kernel Principal Component Analysis (KPCA)}

Based on the related literatures and discussions with working professionals in a pilot survey process, forty two issues that affect the ERP implementation process have been incorporated in the questionnaire. Responses were collected on a five-point Likert-type scale - 'strongly disagree' $(=1)$, 'disagree' $(=2)$, 'somewhat disagree' $(=3)$, 'neutral' $(=4)$, 'somewhat agree' $(=5)$. The principal aim of Factor Analysis (FA) is to identify the highly correlated data items and put them under the umbrella of a new one analyzing correlation present inside the data items. Sometimes FA is called as dimension reduction technique due to its working characteristics. Factor extraction using principal component analysis (PCA), principal axis factoring (PAF), Alpha Factoring (AF), Image factoring (IF), etc. is key process of FA to extract a smaller number of factors (lesser than original number of data items, $n$ ), say $\mathrm{k}(\mathrm{k}<<\mathrm{n})$ that account for the maximum variance in data. In this paper KPCA is utilized for factor extraction process. Working principle of KPCA is illustrated below. 'Kernlab' Package of R library has been used for simulation purpose.

\subsection{Working principle of KPCA}

To find meaningful projections of the data, Principal Component Analysis (PCA) is applied. It is a basis transformation to diagonalize an estimate of the covariance matrix of the data $\mathrm{x}_{\mathrm{k}}, \mathrm{k}=1, \ldots, \mathrm{m}$, $\mathrm{x}_{\mathrm{k}} \in \mathbb{R}^{N}, \sum_{k=1}^{m} x_{k}=0$, can be defined as

$$
C=\frac{1}{m} \sum_{k=1}^{m} x_{j} x_{j}^{T}
$$

Principal components are the orthogonal projections onto the eigenvectors. In Kernel Principal Component Analysis (KPCA) to tackle non linearity input data, the space is mapped into feature space F by

$$
\Phi: \mathbb{R}^{N} \rightarrow F, x \rightarrow X
$$

Subsequently traditional steps of PCA are applied on transformed feature space. Basically PCA attempts to find Eigenvalues $\lambda \geq 0$ and Eigenvectors $V \in F \backslash\{0\}$ from the following covariance matrix satisfying Eq. (2) as follows

$$
\begin{aligned}
& \bar{C}=\frac{1}{m} \sum_{j=1}^{m} \Phi\left(x_{j}\right) \Phi\left(x_{j}\right)^{T} \\
& \lambda V=\bar{C} V
\end{aligned}
$$

All solutions $V$ lie in the span of $\Phi\left(x_{1}\right), \ldots ., \Phi\left(x_{m}\right)$. Hence the following equivalent system may be considered.

$$
\lambda\left(\Phi\left(x_{k}\right) \times V\right)=\left(\Phi\left(x_{k}\right) \times \bar{C} V\right) \quad \text { for all } \mathrm{k}=1, \ldots, \mathrm{m} .
$$

There exists coefficients $\alpha_{1}, \ldots . . \alpha_{\mathrm{m}}$ such that 


$$
V=\sum_{i=1}^{m} \alpha_{i} \Phi\left(x_{i}\right)
$$

An $m \times m$ kernel matrix $(\mathrm{K})$ can be defined as

$$
K\left(x_{i}, x_{j}\right):=\left(\Phi\left(x_{i}\right)^{T} \Phi\left(x_{j}\right)\right)
$$

Usually a kernel function, $K\left(x_{i}, x_{j}\right)$ is used to carry out the inner products in the feature space without explicitly defining transformation $\varphi$. Table 1 displays few well studied kernel functions as reported in literature.

\section{Table 1}

Kernel Functions

\begin{tabular}{ll}
\hline Radial Basis Kernel & $\mathrm{K}\left(\mathrm{x}_{\mathrm{i}}, \mathrm{x}_{\mathrm{j}}\right)=\exp \left(-\left\|x_{i}-x_{j}\right\|^{2} / 2 \sigma^{2}\right)$ \\
Polynomial Kernel & $\mathrm{K}\left(\mathrm{x}_{\mathrm{i}}, \mathrm{x}_{\mathrm{j}}\right)=\left(x_{i}^{T} x_{j}+\gamma\right)^{\delta}$ \\
Sigmoid Kernel & $\mathrm{K}\left(\mathrm{x}_{\mathrm{i}}, \mathrm{x}_{\mathrm{j}}\right)=\tanh \left(\gamma\left(x_{i}^{T} x_{j}\right)+\theta\right)$ \\
\hline
\end{tabular}

Substituting Eq. (3) and Eq. (5) into Eq. (4), yields the following,

$$
m \lambda K \alpha=K^{2} \alpha
$$

To find non-zero Eigenvalues, Eq. (8) is solved.

$$
m \lambda \alpha=K \alpha
$$

Finally, to extract principal components, projections of the image of a test point $\Phi(\mathrm{x})$ into

Eigenvectors $\mathrm{V}^{\mathrm{k}}$ in F yields Eq. (9) as follows,

$$
\left(V^{k} . \Phi(x)\right)=\sum_{i=1}^{m} \alpha_{i}^{k}\left(\Phi\left(x_{i}\right) . \Phi(\mathrm{x})\right)
$$

\section{Analysis based on Intuitionistic Fuzzy TOPSIS}

As discussed earlier, the aim of this study is not just identifying the CSFs of ERP adoption in SMEs but to rank them according to their level of influences on different business performance indicators. Due to the financial constraints, investment on highly ranked issues and timely oversee are immensely sought after by SMEs. To accomplish this research objective, Multi Criteria Decision Making (MCDM) framework has been adopted here. Literature states that solving MCDM problems and searching for an optimal solution are clearly two distinct measures, since the focus of MCDM is to help Decision makers (DMs) evaluate the complex judgments and to carefully analyze data involved in their problems and advance towards an acceptable solution. Its significance in modeling practical problems has resulted in development of several techniques such as TOPSIS, VIKOR, PROMETHEE, AHP, etc. to provide effective solutions. With the rapid evolvement of fuzzy set theory, MCDM techniques are being incorporated with fuzzy set theoretic approaches in order to simulate the exact scenario of the complex problems and to systematically handle the sub problems to reach a feasible solution. As sometimes it is very complex yet critical for a decision-maker to assign a precise performance rating to an alternative for the attributes under consideration. Literature reports many successful studies modeling MCDM problems, utilizing fuzzy set theoretic approaches. In this research, Atanassov's Intuitionistic Fuzzy Set theory have been used in conjugation with TOPSIS method to serve the purpose. The fundamental concepts of it has been discussed in subsequent sub sections. 
An Intuitionistic Fuzzy Set (IFS) A in the universe of discourse $X$ is defined as

$$
\mathrm{A}=\left\{\left\langle x, \mu_{A}(x), v_{A}(x)\right\rangle \mid x \in X\right\}
$$

where $\mu_{A}: X \rightarrow[0,1], v_{A}: X \rightarrow[0,1]$

and the condition

$$
0 \leq \mu_{A}(x)+v_{A}(x) \leq 1
$$

Values of $\mu_{A}(x)$ and $v_{A}(x)$ represent the degree of belongingness and non-belongingness of $x$ to A, respectively.

Ordinary fuzzy set may be expressed as a particular form of IFS in the following form,

$$
\left\{\left\langle x, \mu_{A}(x), 1-\mu_{A}(x)\right\rangle \mid x \in X\right\}
$$

$\mathrm{A}$ is a crisp set if and only if for $\forall x \in X$, either $\mu_{A}(x)=0, v_{A}(x)=1$ or $\mu_{A}(x)=1, v_{A}(x)=0$.

The intuitionistic index of $\mathrm{x}$ in A may be defined as:

$$
\pi_{A}(x)=1-\mu_{A}(x)-v_{A}(x)
$$

It is basically a measure of hesitancy degree of $x$ to $A$. It should be noted that $0 \leq \pi_{A}(x) \leq 1$ for each $x \in X$.

\subsection{Entropy of IFS}

According to the Shannon, entropy function as a measure of uncertainty in a discrete distribution based on the Boltzmann entropy of classical statistical mechanics can be expressed as follows,

$$
H\left(p_{1}, p_{2}, \ldots \ldots p_{n}\right)=-\sum_{i=1}^{n} p_{i} \log \left(p_{i}\right)
$$

where $p_{i}(\mathrm{i}=1,2, \ldots, \mathrm{n})$ are the probabilities of random variable computed from a probability mass function $P$. De Luca and Termini (1972) defined a non-probabilistic entropy formula of a fuzzy set based on Shannon's function on a finite universal set $X=\left\{x_{1}, x_{2}, \ldots \ldots, x_{n}\right\}$ shown in Eq. (14).

$$
E_{L T}(A)=-k \sum_{i=1}^{n}\left[\mu_{A}\left(x_{i}\right) \ln \mu_{A}\left(x_{i}\right)+\left(1-\mu_{A}\left(x_{i}\right)\right) \ln \left(1-\mu_{A}\left(x_{i}\right)\right)\right]
$$

where

$$
k=-\frac{1}{n \ln 2}
$$

Vlachos and Sergiadis (2007) defined the measure entropy of intuitionistic fuzzy set using equation $z$ as follows,

$$
E_{L T}^{I F S}(A)=-\frac{1}{n \ln 2} \sum_{i=1}^{n}\left[\mu_{A}\left(x_{i}\right) \ln \mu_{A}\left(x_{i}\right)+v_{A}\left(x_{i}\right) \ln v_{A}\left(x_{i}\right)-\left(1-\pi_{A}\left(x_{i}\right)\right) \ln \left(1-\pi_{A}\left(x_{i}\right)\right)-\pi_{A}\left(x_{i}\right) \ln 2\right]
$$




\subsection{Intuitionistic Fuzzy TOPSIS Model}

Step 1: Formulation of the problem:

Let us assume Set $A, C$ and $W\left(A=\left\{A_{1}, A_{2}, \ldots, A_{\mathrm{m}}\right\}, C=\left\{C_{1}, C_{2}, \ldots, C_{\mathrm{n}}\right\} \& W=\left\{W_{1}, W_{2}, \ldots, W_{\mathrm{n}}\right\}\right)$ denote the set of $m$ alternatives, $n$ criteria and weights of $n$ criteria respectively.

Weight vectors of criteria follow the condition mentioned below:

$$
\sum_{j=1}^{n} W_{j}=1
$$

where $W_{j}>0$.

Each alternative $\left(\mathrm{A}_{\mathrm{i}}\right)$ is characterized by IFS as:

$$
A_{i}=\left\{\left\langle C_{j}, \mu_{A_{i}}\left(C_{j}\right), v_{A_{i}}\left(C_{j}\right)\right\rangle \mid C_{j} \in C\right\}, \mathrm{i}=1,2, \ldots, \mathrm{m}
$$

Here $\mu_{A_{i}}\left(C_{j}\right)$ and $v_{A_{i}}\left(C_{j}\right)$ measure the degree to which alternative $\mathrm{A}_{i}$ satisfies and does not satisfy the criterion $\mathrm{C}_{\mathrm{j}}$. Following conditions are also hold good,

$$
\begin{aligned}
& \mu_{A_{i}}\left(C_{j}\right) \in[0,1] \\
& v_{A_{i}}\left(C_{j}\right) \in[0,1] \\
& \mu_{A_{i}}\left(C_{j}\right)+v_{A_{i}}\left(C_{j}\right) \in[0,1] \\
& \pi_{A_{i}}\left(C_{j}\right)=1-\mu_{A_{i}}\left(C_{j}\right)-v_{A_{i}}\left(C_{j}\right)
\end{aligned}
$$

The larger the value of intuitionistic index, the higher the hesitation margin about the alternative $A_{i}$ with respect to criterion $\mathrm{C}_{\mathrm{j}}$.

Step 2: Determination of the criteria weights:

According to the work of Hung and Chen, for the decision matrix, $\widetilde{D}=\left[\tilde{x}_{i j}\right]_{m \times n}, \mathrm{i}=1, \ldots \ldots, \mathrm{m}, \mathrm{j}=1, \ldots, \mathrm{m}$ under intuitionistic fuzzy environment, the expected information content emitted from each criterion $\mathrm{C}_{\mathrm{j}}$ is measured by entropy value $\left(E_{L T}^{I F S}\left(C_{J}\right)\right)$ using Eq. (23).

$$
E_{L T}^{I F S}\left(C_{J}\right)=-\frac{1}{m \ln 2} \sum_{i=1}^{m}\left[\mu_{i j}\left(C_{j}\right) \ln \mu_{i j}\left(C_{j}\right)+v_{i j}\left(C_{j}\right) \ln v_{i j}\left(C_{j}\right)-\left(1-\pi_{i j}\left(C_{j}\right)\right) \ln \left(1-\pi_{i j}\left(C_{j}\right)\right)-\pi_{i j}\left(C_{j}\right) \ln 2\right]
$$

The degree of divergence $\left(\mathrm{d}_{\mathrm{j}}\right)$ to represent the inherent contrast intensity of criterion $\mathrm{C}_{\mathrm{j}}$ is computed as follows,

$$
d_{j}=1-E_{L T}^{I F S}\left(C_{J}\right), \mathrm{j}=1,2, \ldots, \mathrm{n}
$$

Entropy weight of $\mathrm{j}^{\text {th }}$ criterion is calculated by

$$
w_{j}=\frac{d_{j}}{\sum_{j=1}^{n} d_{j}}
$$

Step 3: Construction of the weighted intuitionistic fuzzy decision matrix

Weighted intuitionistic fuzzy decision matrix is determined by

$$
\tilde{Z}=W^{T} \otimes \widetilde{D}=W^{T} \otimes\left[\tilde{x}_{i j}\right]_{m \times n}=\left[\hat{x}_{i j}\right]_{m \times n}=\left\langle\hat{\mu}_{i j}, \hat{v}_{i j}\right\rangle=\left\langle 1-\left(1-\mu_{i j}\right)^{W_{j}}, v_{i j}^{W_{j}}\right\rangle
$$


where $W=\left(W_{1}, W_{2}, \ldots \ldots, W_{j}, \ldots \ldots, W_{n}\right)$

Step 4: Identification of Positive Ideal \& Negative Ideal Solution

If $\mathrm{G}$ be a set of benefit criteria and B denotes a set of cost criteria then Fuzzy intuitionistic Positive Ideal Solution $\left(\mathrm{A}^{+}\right)$\& Negative Ideal Solution $\left(\mathrm{A}^{-}\right)$are defined as:

$$
\begin{aligned}
& \left.A^{+}=\left\{\begin{array}{c}
C_{j},\left(\left(\max _{i} \hat{\mu}_{i j}\left(C_{j}\right) \mid j \in G\right),\left(\min _{i} \hat{\mu}_{i j}\left(C_{j}\right) \mid j \in B\right)\right), \\
\left(\left(\min _{i} \hat{v}_{i j}\left(C_{j}\right) \mid j \in G\right),\left(\max _{i} \hat{v}_{i j}\left(C_{j}\right) \mid j \in B\right)\right)
\end{array}\right\rangle \mid i \in m\right\} \\
& \left.A^{-}=\left\{\begin{array}{c}
C_{j},\left(\left(\min _{i} \hat{\mu}_{i j}\left(C_{j}\right) \mid j \in G\right),\left(\max _{i} \hat{\mu}_{i j}\left(C_{j}\right) \mid j \in B\right)\right), \\
\left(\left(\max _{i} \hat{v}_{i j}\left(C_{j}\right) \mid j \in G\right),\left(\min _{i} \hat{v}_{i j}\left(C_{j}\right) \mid j \in B\right)\right)
\end{array}\right\rangle \mid i \in m\right\}
\end{aligned}
$$

Step 5: Ranking of Alternatives

Degree of separations from Fuzzy intuitionistic Positive Ideal Solution $\left(\mathrm{A}^{+}\right)$and Negative Ideal Solution $\left(\mathrm{A}^{-}\right)$are obtained as:

$$
\begin{aligned}
d_{I F S}\left(A_{i}, A^{+}\right) & =\sqrt{\sum_{j=1}^{n}\left[\left(\mu_{A_{i}}\left(C_{j}\right)-\mu_{A^{+}}\left(C_{j}\right)\right)^{2}+\left(v_{A_{i}}\left(C_{j}\right)-v_{A^{+}}\left(C_{j}\right)\right)^{2}+\left(\pi_{A_{i}}\left(C_{j}\right)-\pi_{A^{+}}\left(C_{j}\right)\right)^{2}\right]} \\
d_{I F S}\left(A_{i}, A^{-}\right) & =\sqrt{\sum_{j=1}^{n}\left[\left(\mu_{A_{i}}\left(C_{j}\right)-\mu_{A^{-}}\left(C_{j}\right)\right)^{2}+\left(v_{A_{i}}\left(C_{j}\right)-v_{A^{-}}\left(C_{j}\right)\right)^{2}+\left(\pi_{A_{i}}\left(C_{j}\right)-\pi_{A^{-}}\left(C_{j}\right)\right)^{2}\right]}
\end{aligned}
$$

The relative closeness coefficient (CC) values of respective alternatives in comparison with the intuitionistic fuzzy ideal solutions are measured by

$$
C C_{i}=\frac{d_{I F S}\left(A_{i}, A^{+}\right)}{\left(d_{I F S}\left(A_{i}, A^{+}\right)+d_{I F S}\left(A_{i}, A^{-}\right)\right)}
$$

Ranking of the alternatives is determined by sorting the closeness coefficient (CC) values in descending order. Higher the value of $C C_{i}$ better is the alternative $\mathrm{i}$.

\section{Results}

\subsection{Results of KPCA}

As discussed, KPCA, a nonlinear form of PCA, is adopted for FA. Radial basis function has been used as kernel function. Total seven components, having eigenvalue greater than one, are extracted in this process. Items with loading values less than 0.5 were discarded from further analysis. Separately respective factor reliability scores have also been calculated for validation purpose. As there were thirty one items in the questionnaire, the same number of components were initially extracted. Finally seven extracted components actually account for approximately eighty five percent of total variation. Results are summarized in Table 2.

Discovered seven factors after rotation are: Proper Training (PT), Top Management Support (TMS), Change Management Efficiency (CME), Effective Project Management (EPM), Team Composition (TC), Communication (C) and ERP Package Selection (EPS). 
Table 2

Results of KPCA

\begin{tabular}{|c|c|c|c|c|c|c|c|c|c|}
\hline \multirow[b]{2}{*}{ Components } & \multicolumn{3}{|c|}{ Initial Eigenvalues } & \multicolumn{3}{|c|}{ Extraction Sums of Squared Loadings } & \multicolumn{3}{|c|}{ Rotation Sums of Squared Loadings } \\
\hline & Total & $\begin{array}{c}\% \text { of } \\
\text { Variance }\end{array}$ & $\begin{array}{c}\text { Cumulative } \\
\%\end{array}$ & Total & $\begin{array}{c}\% \text { of } \\
\text { Variance }\end{array}$ & $\begin{array}{c}\text { Cumulative } \\
\%\end{array}$ & Total & $\begin{array}{c}\% \text { of } \\
\text { Variance }\end{array}$ & $\begin{array}{c}\text { Cumulative } \\
\%\end{array}$ \\
\hline 1 & 4.46 & 14.15 & 14.15 & 4.46 & 14.15 & 14.15 & 4.32 & 13.71 & 13.71 \\
\hline 2 & 4.08 & 12.95 & 27.1 & 4.08 & 12.95 & 27.1 & 4.13 & 13.11 & 26.82 \\
\hline 3 & 3.83 & 12.15 & 39.26 & 3.83 & 12.15 & 39.26 & 3.94 & 12.5 & 39.32 \\
\hline 4 & 3.72 & 11.8 & 51.06 & 3.72 & 11.8 & 51.06 & 3.61 & 11.46 & 50.78 \\
\hline 5 & 3.24 & 10.28 & 61.35 & 3.24 & 10.28 & 61.35 & 3.37 & 10.7 & 61.47 \\
\hline 6 & 2.81 & 8.92 & 70.26 & 2.81 & 8.92 & 70.26 & 3.08 & 9.77 & 71.25 \\
\hline 7 & 1.82 & 5.78 & 76.04 & 1.82 & 5.78 & 76.04 & 2.78 & 8.82 & 80.07 \\
\hline 8 & 0.68 & 2.16 & 78.2 & & & & & & \\
\hline 9 & 0.64 & 2.03 & 80.23 & & & & & & \\
\hline 10 & 0.61 & 1.94 & 82.16 & & & & & & \\
\hline 11 & 0.58 & 1.84 & 84.01 & & & & & & \\
\hline 12 & 0.55 & 1.75 & 85.75 & & & & & & \\
\hline 13 & 0.53 & 1.68 & 87.43 & & & & & & \\
\hline 14 & 0.47 & 1.49 & 88.92 & & & & & & \\
\hline 15 & 0.42 & 1.33 & 90.26 & & & & & & \\
\hline 16 & 0.39 & 1.24 & 91.5 & & & & & & \\
\hline 17 & 0.34 & 1.08 & 92.57 & & & & & & \\
\hline 18 & 0.31 & 0.98 & 93.56 & & & & & & \\
\hline 19 & 0.29 & 0.92 & 94.48 & & & & & & \\
\hline 20 & 0.25 & 0.79 & 95.27 & & & & & & \\
\hline 21 & 0.24 & 0.76 & 96.03 & & & & & & \\
\hline 22 & 0.21 & 0.66 & 96.7 & & & & & & \\
\hline 23 & 0.18 & 0.57 & 97.27 & & & & & & \\
\hline 24 & 0.17 & 0.54 & 97.81 & & & & & & \\
\hline 25 & 0.16 & 0.51 & 98.32 & & & & & & \\
\hline 26 & 0.13 & 0.41 & 98.73 & & & & & & \\
\hline 27 & 0.12 & 0.38 & 99.11 & & & & & & \\
\hline 28 & 0.11 & 0.35 & 99.46 & & & & & & \\
\hline 29 & 0.09 & 0.29 & 99.75 & & & & & & \\
\hline 30 & 0.05 & 0.16 & 99.9 & & & & & & \\
\hline 31 & 0.03 & 0.1 & 100 & & & & & & \\
\hline
\end{tabular}

Table 3

Factor Loadings and Reliability scores

\begin{tabular}{|c|c|c|c|}
\hline $\begin{array}{l}\text { Newly Evolved } \\
\text { Dimension }\end{array}$ & Items & Factor Loadings & Cronbach's Alpha \\
\hline \multirow{4}{*}{ 1. Proper Training (PT) } & 1. Investment for education and training & 0.843 & \multirow{4}{*}{0.836} \\
\hline & 2. Employees are part of implementation process & 0.712 & \\
\hline & 3. Targets are well demonstrated & 0.813 & \\
\hline & 4. Rigorous Monitoring & 0.708 & \\
\hline \multirow{5}{*}{$\begin{array}{l}\text { 2. Top Management } \\
\text { Support (TMS) }\end{array}$} & 1. Framing of business plan/vision & 0.709 & \multirow{5}{*}{0.761} \\
\hline & 2. Motivation from senior management & 0.723 & \\
\hline & 3. Timely allocation of funds & 0.882 & \\
\hline & 4. Existence of project champion & 0.701 & \\
\hline & 5. Interventions to resolve conflicts & 0.727 & \\
\hline \multirow{4}{*}{$\begin{array}{l}\text { 3. Change Management } \\
\text { Efficiency (CME) }\end{array}$} & 1. Recognizing the need for change & 0.687 & \multirow{4}{*}{0.803} \\
\hline & 2. Enterprise wide culture and structure management. & 0.808 & \\
\hline & 3. Commitment to change-perseverance and determination & & \\
\hline & 4. IT workforce re-skilling. & 0.711 & \\
\hline \multirow{6}{*}{$\begin{array}{l}\text { 4. Effective Project } \\
\text { Management (EPM) }\end{array}$} & 1. Clear establishments of project scopes & 0.797 & \multirow{6}{*}{0.844} \\
\hline & 2. Early defined project milestones & 0.722 & \\
\hline & 3. Strict adherence to project timelines & 0.828 & \\
\hline & 4. Coordination of project activities & 0.716 & \\
\hline & 5. Tracking milestones and targets & 0.738 & \\
\hline & 6. Assign Responsibility & 0.832 & \\
\hline \multirow{6}{*}{$\begin{array}{l}\text { 5. Team Composition } \\
\text { (TC) }\end{array}$} & 1. Cross-functional team & 0.714 & \multirow{6}{*}{0.811} \\
\hline & 2. Full-time team members & 0.762 & \\
\hline & 3. Best people on team & 0.727 & \\
\hline & 4. Technical knowledge of team members & 0.679 & \\
\hline & 5. Empowered decision makers & 0.802 & \\
\hline & 6. Risk-sharing attitude & 0.837 & \\
\hline \multirow{4}{*}{ 6. Communication (C) } & 1. Communication among stakeholders. & 0.784 & \multirow{4}{*}{0.758} \\
\hline & 2. Effective Communication at all levels. & 0.757 & \\
\hline & 3. Communication of project progress. & 0.821 & \\
\hline & 4. Adequate hardware and Software for communication. & 0.684 & \\
\hline \multirow{4}{*}{$\begin{array}{l}\text { 7. ERP Package } \\
\text { Selection (EPS) }\end{array}$} & 1. Consultation with external experts & 0.734 & \multirow{4}{*}{0.754} \\
\hline & 2. Vigorous study of customization requirement & 0.719 & \\
\hline & 3. Evaluation of vendors & 0.808 & \\
\hline & 4. Cost-benefit analysis & 0.754 & \\
\hline
\end{tabular}


Five manifests of outcome of ERP implementation considered in this study are: improved decision making and planning $(\mathrm{C} 1)$, improvement in productivity $(\mathrm{C} 2)$, improved customer service $(\mathrm{C} 3)$, overall cost reduction (C4) and enhancement of quality (C5). They are considered as criteria for Intuitionistic Fuzzy TOPSIS modelling. The identified seven factors using KPCA are considered as the respective alternatives to be ranked. Linguistic terms shown in table are utilized to rate importance of each CSFs against respective criteria.

\section{Table 4}

Linguistic terms and corresponding Intuitionistic Fuzzy Numbers

\begin{tabular}{llll}
\hline Linguistic Terms & $\begin{array}{l}\text { Intuitionistic Fuzzy } \\
\text { Numbers }\end{array}$ & Linguistic Terms & $\begin{array}{l}\text { Intuitionistic Fuzzy } \\
\text { Numbers }\end{array}$ \\
\hline Extremely High $(\mathrm{EH})$ & {$[1.00,0.00]$} & Medium $(\mathrm{M})$ & {$[0.50,0.40]$} \\
Very Very High $(\mathrm{VVH})$ & {$[0.90,0.10]$} & Medium Low (ML) & {$[0.40,0.50]$} \\
Very High $(\mathrm{VH})$ & {$[0.80,0.10]$} & Low $(\mathrm{L})$ & {$[0.25,0.60]$} \\
High $(\mathrm{H})$ & {$[0.70,0.20]$} & Very Low $(\mathrm{VL})$ & {$[0.10,0.75]$} \\
Medium High $(\mathrm{MH})$ & {$[0.60,0.30]$} & Very Very Low (VVL) & {$[0.10,0.90]$} \\
\hline
\end{tabular}

The seven alternatives, i.e., CSFs to be ranked are: PT (A1), TMS (A2), CME (A3), EPM (A4), TC (A5), C (A6) \& EPS (A7) as discussed in earlier section. The Intuitionistic Fuzzy Decision Matrix after consultation with experts is shown in Table 5.

\section{Table 5}

Intuitionistic Fuzzy Decision Matrix

\begin{tabular}{llllll}
\hline & C1 & C2 & C3 & C4 & C5 \\
\hline A1 & {$[0.70,0.20]$} & {$[0.90,0.10]$} & {$[0.70,0.20]$} & {$[0.70,0.20]$} & {$[0.80,0.10]$} \\
A2 & {$[0.90,0.10]$} & {$[0.80,0.10]$} & {$[0.70,0.20]$} & {$[0.60,0.30]$} & {$[0.60,0.30]$} \\
A3 & {$[0.50,0.40]$} & {$[0.70,0.20]$} & {$[0.70,0.20]$} & {$[0.60,0.30]$} & {$[0.70,0.20]$} \\
A4 & {$[0.90,0.10]$} & {$[0.80,0.10]$} & {$[0.90,0.10]$} & {$[0.80,0.10]$} & {$[0.70,0.20]$} \\
A5 & {$[0.60,0.30]$} & {$[0.70,0.20]$} & {$[0.80,0.10]$} & {$[0.50,0.40]$} & {$[0.70,0.20]$} \\
A6 & {$[0.90,0.10]$} & {$[0.60,0.30]$} & {$[0.50,0.40]$} & {$[0.40,0.50]$} & {$[0.50,0.40]$} \\
A7 & {$[0.70,0.20]$} & {$[0.70,0.20]$} & {$[0.80,0.10]$} & {$[0.60,0.30]$} & {$[0.80,0.10]$} \\
\hline
\end{tabular}

The weighted Intuitionistic Fuzzy Decision Matrix is obtained using entropy based method as shown in Table 6.

\section{Table 6}

Weighted Intuitionistic Fuzzy Decision Matrix

\begin{tabular}{llllll}
\hline & C1 & C2 & C3 & C4 & C5 \\
\hline A1 & {$[0.21,0.73]$} & {$[0.37,0.63]$} & {$[0.22,0.72]$} & {$[0.21,0.73]$} & {$[0.28,0.63]$} \\
A2 & {$[0.36,0.64]$} & {$[0.28,0.63]$} & {$[0.22,0.72]$} & {$[0.16,0.79]$} & {$[0.17,0.78]$} \\
A3 & {$[0.13,0.84]$} & {$[0.22,0.72]$} & {$[0.22,0.72]$} & {$[0.16,0.79]$} & {$[0.22,0.72]$} \\
A4 & {$[0.36,0.64]$} & {$[0.28,0.63]$} & {$[0.38,0.62]$} & {$[0.27,0.64]$} & {$[0.22,0.72]$} \\
A5 & {$[0.16,0.79]$} & {$[0.22,0.72]$} & {$[0.28,0.62]$} & {$[0.13,0.84]$} & {$[0.22,0.72]$} \\
A6 & {$[0.36,0.64]$} & {$[0.17,0.78]$} & {$[0.13,0.83]$} & {$[0.09,0.87]$} & {$[0.13,0.83]$} \\
A7 & {$[0.21,0.73]$} & {$[0.22,0.72]$} & {$[0.28,0.62]$} & {$[0.16,0.79]$} & {$[0.28,0.63]$} \\
\hline
\end{tabular}

Subsequently the positive ideal and negative ideal solutions have been identified and closeness coefficient values of respective alternatives (CSFs) are calculated. Table 7 displays closeness 
coefficient values and respective ranks of each factor. Proper Training (PT) has been found to be the most important factor among seven factors.

Table 7

The closeness coefficients and ranking

\begin{tabular}{llllllll}
\hline CSF & PT & TMS & CME & EPM & TC & C & EPS \\
\hline $\begin{array}{l}\text { Closeness } \\
\text { coefficient }\end{array}$ & O.608 & 0.380 & 0.246 & 0.533 & 0.325 & 0.266 & 0.406 \\
Ranking & 1 & 4 & 7 & 2 & 5 & 6 & 3 \\
\hline
\end{tabular}

\section{Findings \& Discussions}

The study has attempted to identify the key issues of successful ERP adoption process in Indian SMEs. According to the empirical analysis, it can be inferred that proper training (PT) is the most significant one followed by effective project management (EPM). SMEs often lag behind world class players due to inadequate knowledge about advanced tools and techniques. The crux of ERP lies on effective management of data. If adequate training is not imparted then expensive ERP packages hardly will add any value on overall business process as far as SMEs are concerned. Hence the employees must be properly educated to understand the operational processes, implementation issues, cost, etc. The second ranked factor, efficient project management also contributes to overall success, significantly. Scope and goals of the project should be defined and clarified at an early stage of ERP adoption process. Benchmarks should be set and continuous monitoring of the critical activities is required as well. Skill of project managers also has a crucial effect on overall success.

The third one, ERP package selection is another critical task specifically for SME industrial sector. Exhaustive efforts must be put to analyze the functionalities provided by different potential packages, customization need, vendors' cooperation level etc. As third party consultants opinions are not always affordable SME's in general prefer packages having lesser implementation time, cost with lesser degree of customization (Everdingen et al., 2000). Top management support throughout the implementation project in terms of catering motivation, encouragement, timely approval of available funds, etc. Team competence in terms of knowledge, experience, risk taking attitude largely affects the outcomes of the project. Smooth and non-disruptive flow the project are determined by the team members with high technical knowhow and their skills in applying the knowledge in appropriate time. Essentially, ERP brings about cultural change. Thus, effective communication to share critical information about various activities, achievements, obstacles in timely manner among the team members act as key determinants of ERP success (Sumner, 1999). Change management can effectively be managed by engaging the users in design and implementation process. Proper Training also affects the entire change management process.

\section{Conclusion}

This study has presented an empirical work based on a novel framework incorporating KPCA and Intuitionistic Fuzzy TOPSIS to assess the role of various factors affecting ERP adoption process in SME industrial sector in India. It has become the mandate that, organizations must consolidate their operations, build partnership with other key members of the supply chain for sharing of resources, knowledge and information not only to gain competitive advantage but also to mitigate risk while operating in a volatile business environment. To reap the benefits derived out of effective utilization of the ERP system, it is essential to implement it properly. The findings of the study may therefore assist SMEs to formulate suitable implementation strategies for put ERP system in place for leveraging the benefits of ERP to improve the overall business process and thereby to gain inclusive business growth. However, further study can be made to ascertain potential impact of ERP system to overall business 
results. Also, success factors for ERP implementation can further be studied on cluster wise where each cluster consists of SMEs performing similar business operations and operating with similar products.

\section{Acknowledgement}

The authors would like to thank the anonymous referees for constructive comments on earlier version of this paper.

\section{References}

Abid, T., Altaf, M., Yousaf, U \& Bagram, M. (2012). Entrepreneur as an authentic leader: A study of small and medium sized enterprises in Pakistan. Management Science Letters, 2(7), 2355-2360.

Annual Report (2014-15). Ministry of Micro, Small and Medium Enterprises. Government of India.

Basua, R., Upadhyay, P \& Dan, P. (2011). Factors influencing ERP implementation in Indian SMEs: An empirical analysis. Management Science Letters, 1(2), 89-98.

De Luca, A., \& Termini, S. (1972). A definition of a nonprobabilistic entropy in the setting of fuzzy sets theory. Information and control, 20(4), 301-312.

Everdingen, Y., Hillergersberg, J. \& Waarts, E. (2000). ERP adoption by European midsize companies. Communications of ACM, 43(4), 27-31.

Habibzadeh, M., Meshkani, F \& Shoshtari, A. (2016). Identifying and ranking the factors affecting entrepreneurial marketing to facilitate exports. Management Science Letters, 6(4), 309-314.

Holland, P., Light, B. \& Gibson, N. (1999). A critical success factors model for enterprise resource planning implementation. Proceedings of the 7th European Conference on Information Systems, 1, 273-297.

Huin, S.F. (2004). Managing deployment of ERP systems in SMEs using multi-agentsll. International Journal of Project Management, 22(6), 511-17.

Hwang, C. L., \& Yoon, K. (1981). Methods for multiple attribute decision making. In Multiple Attribute Decision Making (pp. 58-191), Springer Berlin Heidelberg.

Jutla, D., Bodorik, P. \& Dhaliwal, J. (2002). Government Support for the Readiness of Small and Medium Sized Enterprises. Proceedings of 35th Annual Hawaii International Conference on Systems Sciences, Hawaii.

Knight, G. (2000). Entrepreneurship and marketing strategy: The SME under globalization. Journal of International Marketing, 8(2), 12-32.

Mandal, P., \& Gunasekaran, A. (2002). Application of SAP R/3 in on-line inventory control. International Journal of Production Economics, 75(1), 47-55.

Motwani, J., Mirchandani, D., Madan, M. \& Gunasekaran, A. (2002). Successful implementation of ERP projects: Evidence from two case studies. International Journal of Production Economics, 75(1), 83-96.

Orougi, S. (2015). Recent advances in enterprise resource planning.Accounting, 1(1), 37-42.

Palaniswamy, R. \& Frank, T. (2000). Enhancing manufacturing performance with ERP systems. Information Systems Management, 17(3), 43-55.

Rao, S.S. (2000). Enterprise resource planning: business needs and technologies. Industrial Management \& Data Systems, 100(2), 81-88.

Siau, K. (2004). Enterprise resource planning (ERP) implementation methodologies. Journal of Database Management, 15(1), 1-6.

Shanks, G. (2000). A model of ERP project implementation. Journal of Information Technology, 15(4), 289-304.

Sumner, M. (1999). Critical success factors in enterprise wide information management systems projects. Proceedings of the Americas Conference on Information Systems (AMCIS), 232-244.

Vlachos, I. K., \& Sergiadis, G. D. (2007). Intuitionistic fuzzy information-applications to pattern recognition. Pattern Recognition Letters, 28(2), 197-206.

Vogt, C. (2002). Intractable ERP a comprehensive analysis of failed enterprise-resources-planning projects. ACM SIGSOFT, 27(2), 62-68. 
Woo, H.S. (2007). Critical success factors for implementing ERP: The case of a Chinese electronics manufacturer. Journal of Manufacturing Technology Management, 18(4), 431-442.

Yusuf, Y., Gunasekaran, A. \& Wu, C. (2006). Implementation of enterprise resource planning in China. Technovation, 26(12), 1324-1336. 